The Research Journal of the Costume Culture

[Original Article]

Received January 13, 2017

Accepted February 27, 2017

${ }^{\dagger}$ Corresponding author

(channyblue@hanyang.ac.kr)

ORCID

Naan Ju

http://orcid.org/0000-0002-9880-5872

Kyu-Hye Lee

http://orcid.org/0000-0002-7468-0681

Jiyeon Lee

http://orcid.org/0000-0002-1448-1541

\section{The effect of consumer's need for uniqueness on fashion orientation and consumption values}

\author{
Naan Ju, Kyu-Hye Lee and Jiyeon Lee ${ }^{\dagger}$
}

Dept. of Clothing \& Textiles, Hanyang University, Korea

\section{독특성에 대한 욕구가 패션성향과 소비가치에 미치는 영향 \\ 주나안 · 이규혜· 이지연 ${ }^{\dagger}$ \\ 한양대학교 의류학과}

\begin{abstract}
People tend to maintain and express their individuality in unique ways. Consumer's need for uniqueness is defined as an individual's pursuit that differentiates themselves from others, thereby developing and enhancing their personal identities. This study examined the effect of consumers' need for uniqueness on fashion orientation and consumption values. Data were collected through a questionnaire survey distributed to people visiting the fashion show center during Seoul Fashion Week. The survey questions were designed using the 5-point Likert scale and Cronbach's a value of questions was reliable as $.628-.862$. The study's results indicate that people with high need for uniqueness are very interested in fashion and think that is important to be well-dressed. In addition, the results suggest that people with high needs for unusual choices who enjoy challenging the prevailing taste of people want to be fashion leaders and are attracted to products that express their personality well. And people with high needs for creative choices and incompliant choices value their own satisfaction and happiness with the products. On the other hand, consumer's needs for incompliant choices have a negative effect on social value. As a result, people with high needs for incompliant choices would break social norms rather than consider social status and reputation when they purchase fashion products. The concluding section of the paper discusses the implications of this research for fashion companies.
\end{abstract}

Keywords: consumer's need for uniqueness(소비자의 독특성 욕구), fashion orientation (패션성형), consumption values(소비가치)

\section{Introduction}

사람들은 자신만의 독특한 개성을 유지하고 표출하여 다른 사람과 구별되고자 하는 경향을 가지고 있다. 이러한 욕구는 일반적으로 규범에 대한 순응이라는 사회 적 압력과 상충되며, 아직까지 많은 사회에서 사회적 규범에 반하는 행동은 비난의 대상이 된다. 그러나 소비행위를 통한 독특성 욕구의 표출은 반사회적이지 않을 수 있으며, 오히려 자존감을 높이고, 부정적인 감정을 해소하는 긍정적 기능을 가질 
수 있다. Snyder and Fromkin(1977)은 다른 사람과 구별되고자 하는 이러한 개인의 욕구를 독특성 욕구 라 칭하고, 독특성 욕구에 따른 사회행동의 개인차를 연구하였으며, Tian, Bearden, and Hunter(2001)는 소 비자 행동에서 독특성 욕구라는 개념을 제안하고, 이 를 측정하기 위한 척도를 개발한 바 있다. 소비자의 독 특성 욕구(consumers' need for uniqueness)는 상품의 습 득과 사용, 처분과정을 타인과 상대적으로 차별적으 로 함으로써 자기 이미지와 사회적 이미지의 발달과 고 양을 도모하려는 욕구로 하나의 개인특질을 말한다 (Tian et al., 2001). 즉, 소비자의 독특성 욕구란 소비 행위를 통해 자신의 개성 또는 정체성을 타인과 구별 적으로 표현하려는 성향으로 사람마다 정도의 차이가 있는 하나의 성격특성이라고 할 수 있다. 그래서 어떤 사람들은 일반적 또는 대중적이라고 할 수 있는 디자 인, 색상, 형태 등의 상품을 사용함으로써 타인과 자 신의 적극적인 구별을 시도하지 않는 반면, 어떤 사람 들은 일반인의 사고나 관습으로는 쉽게 받아들일 수 없는 상품을 사용함으로써 타인과 자신을 확실히 구 분하기를 원할 수 있다. 현재 우리 사회는 대중사회에 서 개인사회로 빠르게 변화하고 있으며, 사회적으로 도 개인의 개성을 인정하고 수용하려 하고 있다. 또 한, 소비자들의 기호는 점점 까다로워지고, 소비 성향 이 개인화, 고도화 되면서 소비자들은 이전보다 자유 롭게 자신의 개성을 소비를 통하여 표현하고, 다른 사 람들과 자신을 구별하고자 하는 욕구를 표출하고 있 으며, 따라서 독특성 욕구는 과거보다 훨씬 중요한 개 념으로 여겨지고 있다.

그러나 그 동안 의류학에서는 독특성 욕구의 개념 보다는 이와 상대되는 개념이라고 할 수 있는 동조성 에 관한 연구들이 많았으며, 독특성 욕구를 패션성향 이나 소비가치와 연결시켜 연구한 경우는 많지 않았 다. 따라서 본 연구에서는 특별하게 지각되어 다른 사람과 차별되고자 하는 성향을 나타내는 소비자 독 특성 욕구요인이 소비자의 패션성향과 소비가치에 미치는 영향을 알아보고자 한다.

\section{Literature Review}

\section{Consumer's need for uniqueness}

독특성이라는 개념은 심리학적 비정상성에서 출발
(Snyder \& Fromkin, 1977)하였으며, 소비과정에서 빈 번하게 발생하는 것이 아니기 때문에, 최근까지 소비 자의 독특성과 소비를 연관시킨 연구는 많지 않았다. 또한 독특성이라는 개념이 흔하거나 일반적이라기 보 다, 특이한 선택을 의미하고 있기 때문에 보통 소비 자의 속성이라고 하기는 어렵다. 그러나, 소비를 통해 타인과 자신을 차별화 하고자 하는 소비자의 독특성 욕구는 시각적 표현 능력이 강하고, 유행에 민감한 패션 제품의 구매 시 비교적 많이 나타나며, 이러한 욕구는 스타일과 유행의 변화를 촉진시킴으로써 패션 산업 전체를 발전시키는 중요한 원동력이 될 수 있 다.

개인의 독특성 욕구에 관한 연구는 1970년대 심리 학과 사회학에서 시작되었으며, 1980년대 이후에는 소 비자 행동과 마케팅 분야에서 연구들이 진행되어 왔 다. 그 동안 독특성에 대한 연구들은 크게 두 가지 방 향으로 이뤄져 왔는데, 초기에는 독특성에 대한 개념 적, 조작적 정의와 측정도구의 개발 및 타당성 검증에 관한 연구들(Gim \& Ryu, 2003; Lynn \& Harris, 1997; Snyder \& Fromkin, 1977; Tepper \& Hoyle, 1996; Tian et al., 2001; Tian \& Mckenzie, 2001)이 진행되 었으며, 이후 제품이나 브랜드를 선정하는 데 있어 독 특성의 영향에 관한 연구들(Bertrandias \& Goldsmith, 2006; Holt, 1995; Jeon \& Park, 2005; Knight \& Kim, 2007; Park \& Park, 2016; Yuan \& Kim, 2015)이 이 루어져 왔다. 독특성 욕구와 충동구매에 관한 Yuan and $\operatorname{Kim}(2015)$ 의 연구에 따르면 독특성 욕구는 패션 제품에 대한 충동구매에 영향을 미치며, 특히 개인 이 미지를 표출하려는 성향이 강한 사람들일수록 충동 구매 성향이 높다고 하였다. 한편, 일본 소비자의 독 특성 욕구에 관한 Knight and Kim (2007)의 연구에 따르면, 브랜드 가치는 독특성 욕구의 차원에 따라 다르게 지각되며, 비대중적 선택 욕구는 지각된 감정 가치에 영향을 미쳐, 결과적으로 독특한 의사 결정을 하게 된다고 하였다(Simonson \& Nowlis, 2000). 즉, 소비자의 독특성은 소비자의 구매행동을 설명하는 선 행변인이며, 특정한 제품이나 브랜드를 선호하고, 반 복적으로 구매하는 가능성에 대해 모색하는 방향으 로 연구가 진행되어 왔다.

독특성 욕구와 의복과의 관련성은 Snyder and Fromkin(1977)이 지적한 바와 같이, 의복은 하나뿐인 
자기(unique self)의 투영 또는 연장물로 타인과 구별 하는 역할을 수행하며, 따라서 의복의 선택은 곧 독특 성을 추구하는 행동이다. 패션 소비자의 독특성 욕구 에 대한 연구를 살펴보면, Workman and Kidd(2000)는 패션선도자 집단에 속하는 의견선도자, 혁신자, 혁신 적 전달자는 서로 다른 집단이라고 할 수 없으나, 선도 자는 추종자에 비해 더 높은 독특성 욕구를 가진다고 하였다. 즉, 독특성 욕구가 강한 사람들은 사회적 비난 을 감수하고, 자신의 독특함을 행동적으로 나타내는 사람으로 새롭고 특이한 상품에 관심이 많고 혁신적인 소비 행동을 보인다. 또한 이들은 의복 선택에서도 혁 신성이 강하며, 새로운 스타일의 착용과 채택을 먼저 시도할 뿐만 아니라, 패션 스타일에 대한 정보탐색에 도 적극적이며 최신 스타일을 구입하기 위해 기꺼이 더 많은 돈을 지불한다고 하였다(Workman \& Kidd, 2000).

한편, Tian and Makenzie(2001)에 따르면, 소비자 의 독특성 욕구는 다음과 같이 독창적 선택을 통한 역 순응(creative choice counterconformity), 비대중적 선택 을 통한 역순응(unpopular choice counterconformity), 유사성의 회피(avoidance of similarity)의 3 가지 요인 으로 구성되어 있다. 사람들은 개성이나 정체성을 유 지 또는 고양시키기 위해 자신을 잘 나타낼 수 있는 물질적 상품을 이용하여 자기만의 개인적 스타일을 창조하며(Kron, 1983), 이것은 최초의 또는 독특한 상 품을 통해, 그리고 이러한 상품의 수집과 진열을 통해 가능하다(Belk, 1988; Kron, 1983). 독창적 선택을 통 한 역순응(creative choice counterconformity)은 타인 과 사회적으로 차별적이면서도 타인들이 좋은 선택 이라고 긍정적으로 평가할 수 있는 것을 선택하고자 노력하는 것으로 마켓 메이븐들이 독창적 선택 욕구 를 가진 소비자로 평가 받는다(Solomon \& Rabolt, 2004). 비대중적 선택을 통한 역순응(unpolular choice counterconformity)이란 타인과 그들 자신을 차별하기 위해 사회적으로 받아들여지지 않을 위험을 감수하 면서까지 집단의 규칙 또는 관습을 깰 수 있는 상품 (상표)을 선택하거나 사용하는 것을 말한다. 비대중적 선택은 일종의 비정상적인 취향으로 평가를 받을 수 도 있으나, 독특함을 나타내기 위한 행동으로 규칙을 깨고, 사회적 불승인의 위험을 무릅쓰는 사람들은 종 종 바람직한 특질을 가진 것으로 평가 받으며, 이로
인해 자기 이미지를 고양시킬 수도 있다(Gross, 1977). 게다가, 어떤 상품을 처음으로 사용하는 비대중적 선 택이 나중에 사회적으로 수용되는 경우에는 이들은 혁신자 또는 유행선도자로서 긍정적인 존재로가 될 수 있다(Hecket, 1989). 유사성 회피(avoidance of similarity) 란 소비자들이 자신의 독특함을 재정립하기 위해 흔 하게 되어버린 제품에 대한 흥미를 상실하거나, 사용 을 중단하는 것을 말한다. 처음 시장에 나왔을 때에는 독특한 것이었던 상품이나 소비행동도 점차 많은 소 비자들이 수용하게 되면 더 이상 독특하지 않은 평범 한 것이 되고 만다. 독특성 욕구가 높은 사람들은 이처 럼 평범하거나 흔하다고 지각한 상품이나 브랜드를 구매하고 사용하는 것을 낮게 평가하며, 이를 회피하 기 위해서 자신이 수용했던 상품을 처분하거나, 사용 을 중단하고 새로운 대체물을 찾는다. 그러나 독특한 상품의 사용을 통해 만들어낸 독창적인 자기 이미지 와 사회적 이미지는 미디어와 무역의 발달로 많은 사 람들이 빠르고 쉽게 모방할 수 있게 되면서 점점 그 수명이 짧아지고 있다.

독특성 욕구는 앞서 서술한 것처럼 많은 선행 연구 들에서 다양하게 정의되어 왔으나, 본 연구에서는 상 품의 구매와 사용, 처분행동을 타인과 상대적으로 차 별적으로 함으로써 자기 이미지 및 사회적 이미지를 고양시키고자 하는 욕구이자, 하나의 개인특질로 정의 하고자 한다.

\section{Fashion orientation}

패션은 새로운 소비를 창출하는 종합적인 사회현 상으로써의 특징을 가지고 있으며, 개인의 삶의 많은 부분에서 영향을 받으므로 그들의 라이프 스타일 혹은 가치를 이해하지 않고는 설명할 수 없다(Kim, 2008). 소비자의 패션성향(fashion orientation)이란 소비자가 그들의 삶에 있어 옷 혹은 패션을 얼마나 중요하게 생각하는지를 보여주는 것으로, 패션산업에서 소비자 의 행동을 설명하는 가장 중요한 변수 중 하나이다. 따라서 의복 자체에 대한 관여에서 출발하여 패션 제 품의 사용과 소비에 대한 다양한 측면을 나타내는 패 션 성향은 패션상품에 대한 개인의 선택과 채택의 근 거를 설명하는 개념으로 사용되고 있으며, 패션산업 에서는 시장세분화의 변수로 자주 사용되고 있다. 그 동안 진행되어 온 패션성향에 관한 연구들을 살펴보 
면, Lumpkin(1985)은 패션성향을 개인이나 집단의 특 성을 표현하는 시장세분화의 기준으로 사용하였으며, Workman and Kidd(2000)는 패션에 대한 유사한 성 향을 가진 소비자는 신상품이나 패션잡지에 대해서 도 유사한 태도를 보인다는 것을 밝혔다. Gutman and Mills(1982)는 기존의 연구를 바탕으로 하여 패션 리 더십, 패션 관심, 의복 중요성, 반 패션태도의 네 가지 요인으로 구성된 패션성향 측정척도를 개발하였다. 국내 연구에서는 패션성향이라는 용어보다는 의복태 도(Kim \& Chung, 2000)나 패션지향성(Lee \& Choi, 2011)이라는 포괄적인 어휘가 주로 사용되었다. 그러 나 본 연구에서는 패션산업의 소비자 행동은 결국 상 품의 선택과 구매로 결정되므로 좀 더 직접적인 변수 를 사용하여 패션성향을 분석하고자 개인의 패션성 향 결정변수 중에서 소비성향을 나타내는 변수로 한 정하여 사용하였다.

\section{Consumption values}

소비가치는 소비에 대한 특정 가치로 소비자의 선 택 행동에 큰 영향을 미치며, 따라서 소비자를 구분하 여 판단하는 기준으로 사용되어 왔다. 소비가치에 관 한 초기 연구는 Vinson, Scott, and Lamont(1977)에 의해서 제안되었으며, 그들은 개인의 가치라는 개념 은 매우 추상적이고 일반적이기 때문에, 구체적인 소 비상황에서 어떤 한 제품이나 서비스의 구매행동에 직 접적인 영향력을 발휘하기는 어려우며, 개인의 가치는 소비관련 가치를 통해 구체적인 제품 구매 행동에 영향 을 끼친다는 사실을 입증하였다. 이후 Sheth, Newman, and Gross(1991)는 기존의 가치 체계들이 갖는 한계 점을 지적하고, 200 개 이상의 선택사항을 테스트하여 소비행동과 관련이 있는 가치만을 추출, 소비가치라 는 용어를 사용하여 정리하였다. Sheth et al.(1991)에 따르면 소비가치는 기능적 가치, 사회적 가치, 감정적 가치, 상황적 가치, 진귀적 가치를 포함하며, 소비자 의 의사결정은 이 다섯 가지 소비가치들 중의 어느 하나, 혹은 모두에 의해 영향을 받을 수 있다. 그러나 Sheth et al.(1991)의 소비가치는 소비와 관련된 가치 만을 체계적으로 정리하였다는데 그 의의가 있으나, 실질적인 문항은 제공하지 못했다는 한계점을 가지 고 있다. 또한 상황가치는 연구목적 또는 특정 제품 의 상황에 따라 문항의 일관성을 유지하기 어려우며,
나머지 소비가치에 비해 문항의 신뢰도가 낮은 편이 다. 따라서 본 연구에서는 이러한 한계점을 극복하기 위해 상황가치 대신에 소비자의 소비욕구를 반영한 차별적 개성추구 가치를 포함하여 측정항목을 구성 하였다.

\section{Methods}

\section{Research question}

본 연구는 소비자의 독특성 욕구가 패션성향과 소 비가치에 미치는 영향을 알아보기 위해 다음과 같은 연구 문제를 설정하였다.

연구문제 1. 소비자의 독특성 욕구가 소비자의 패 션성향에 미치는 영향을 알아본다.

연구문제 2. 소비자의 독특성 욕구가 소비자의 소 비가치에 미치는 영향을 알아본다.

\section{Measuring instruments and data collection}

소비자의 독특성 욕구에 관한 문항은 Gim and Ryu (2003)의 한국판 소비자 독특성 욕구 척도를 수정, 보 완하여 총 31 문항 중 24 문항을 최종 설문에 사용하였 다. 소비자의 패션성향에 관한 문항은 Gutman and Mills(1982)의 17 문항을 사용하였으며, 선행 연구에 는 반 패션 태도(anti-fashion attitude) 요인을 제외하 였지만, 본 연구에서는 독특성 욕구가 높은 소비자는 기존의 유행을 거부하는 성향이 높을 것으로 판단되어 반 패션 태도를 포함한 네 가지 차원으로 설문을 구 성하였다. 소비 성향의 측정은 Sheth et al.(1991)의 소비가치이론을 기초로 한 $\operatorname{Kim}(1999)$ 과 $\operatorname{Kim}(2010)$ 의 문항을 근거로, 27 문항을 사용하였다.

본 연구는 독특성 욕구가 높은 사람들이 많이 찾을 것으로 예상되는 이벤트로 서울 패션 위크를 선정하 고 해당 기간 동안 디자이너 컬렉션을 참관한 남녀 100 명을 대상으로 설문을 실시하였다. 이 중 불성실 한 응답을 제외 하고 75 부가 최종 분석에 사용되었 다. 자료 분석은 PASW 18.0을 이용하였으며, 요인분 석, 신뢰도 분석, 회귀분석을 실시하였다.

\section{N. Results}

\section{Socioeconomic characteristics of respondents}


표본구성은 남성이 $24 \%$, 여성이 $76 \%$ 였으며, 연령 은 20 대(53.3\%)와 10 대(38.7\%)가 가장 많았다. 최종 학력은 대학교 재학 $45.3 \%$, 고등학교 재학 $28 \%$, 대학 교 졸업 $24 \%$, 대학원 졸업 $2.7 \%$ 의 순이었으며, 거주 지역은 서울, 경기가 $81.4 \%$ 으로 대부분을 차지하였다. 응답자들의 의복행동을 살펴보면, 한달 평균 의복 구 매 횟수는 3.8 회, 한달 평균 의복비는 10 만원 이상 30 만원 미만이 $58.1 \%$ 을 차지했으며, 50 만원 이상도 $10.7 \%$ 를 차지했다.

\section{Factor analysis and reliability verification}

1) Factor analysis and reliability verification of consumer's need for uniqueness

소비자 독특성 욕구는 24 문항 중 주성분 분석과 Varimax 회전을 실시 한 결과, 요인 부하량이 낮은 4 문 항을 제외한 20 문항을 분석에 사용하였다. 소비자의
독특성 욕구 요인은 기존 연구와 달리 4 개 요인이 도 출되었으며, 누적 설명력은 $55.961 \%$, Cronbach's $\alpha$ 값 은 .628 .835로 나타나 적정한 신뢰도 수준을 보였다 (Table 1).

요인 1 은 자신만의 스타일을 창조하기 위해 노력 하고 독특한 제품을 구매한다는 내용의 9문항으로 구 성되어 ‘독창적 선택'요인으로, 요인 2는 이미 인기를 끌거나 대중들 사이에서 흔하게 되어버린 상품에 대 해서는 흥미를 상실하거나 사용을 중단하는 내용으 로 총 5문항이 포함되어 '유사성 회피'요인으로 명명 하였다. 요인 3 은 규칙 또는 관습을 깨거나 사회적 불 승인의 위험을 감소하면서도 자신만의 독특한 스타 일을 위해 노력한다는 내용의 4 문항이 포함되어 '비 순응적 선택'요인으로 명명하였고, 마지막으로 요인 4 는 기존의 유행에 도전하거나 사람들이 받아들이기 힘든 대담한 옷차림을 한다는 내용의 2 문항이 구성되 어 '비대중적 선택'요인으로 명명하였다. 소비자의 독

$<$ Table 1> Factor analysis and reliability verification of consumer's need for uniqueness

\begin{tabular}{|c|c|c|c|c|c|c|}
\hline & Factors & Items & $\begin{array}{l}\text { Factor } \\
\text { loading }\end{array}$ & $\begin{array}{l}\text { Eigen- } \\
\text { value }\end{array}$ & $\begin{array}{c}\text { Variance } \\
\text { (cum. var.) }\end{array}$ & $\begin{array}{c}\text { Cronbach's } \\
\alpha\end{array}$ \\
\hline \multirow{9}{*}{$\begin{array}{l}\text { Consumer's } \\
\text { needs for } \\
\text { uniqueness }\end{array}$} & \multirow{9}{*}{$\begin{array}{c}\text { Creative } \\
\text { choice }\end{array}$} & $\begin{array}{l}\text { Having a discerning eye for products } \\
\text { that are interesting and unique assists } \\
\text { me in establishing a distinctive image. }\end{array}$ & .750 & \multirow{9}{*}{4.956} & \multirow{9}{*}{$\begin{array}{c}19.664 \\
(19.664)\end{array}$} & \multirow{9}{*}{.835} \\
\hline & & $\begin{array}{l}\text { I have purchased one-of-a-kind products } \\
\text { or brands from time to time as a way to } \\
\text { create a more distinctive personal image. }\end{array}$ & .712 & & & \\
\hline & & $\begin{array}{l}\text { I often look for unique products or } \\
\text { brands so that I create my own style. }\end{array}$ & .705 & & & \\
\hline & & $\begin{array}{l}\text { I like products and brands that express } \\
\text { my individuality. }\end{array}$ & .690 & & & \\
\hline & & $\begin{array}{l}\text { I enthusiastically try to develop my } \\
\text { personal uniqueness by buying unique } \\
\text { products or brands. }\end{array}$ & .635 & & & \\
\hline & & $\begin{array}{l}\text { I often combine possessions in such a } \\
\text { way that I create a personal image for } \\
\text { myself that can't imitate. }\end{array}$ & .589 & & & \\
\hline & & $\begin{array}{l}\text { I often try to find a more distinctive } \\
\text { products among manufactured goods } \\
\text { because I enjoy being original. }\end{array}$ & .555 & & & \\
\hline & & $\begin{array}{l}\text { I often explore new products or brands } \\
\text { that increase my personal uniqueness. }\end{array}$ & .553 & & & \\
\hline & & $\begin{array}{l}\text { I often think about what I buy and how } \\
\text { I use it to create a more unusual personal } \\
\text { image. }\end{array}$ & .518 & & & \\
\hline
\end{tabular}


$<$ Table 1> Continued

\begin{tabular}{|c|c|c|c|c|c|c|}
\hline & Factors & Items & $\begin{array}{l}\text { Factor } \\
\text { loading }\end{array}$ & $\begin{array}{l}\text { Eigen- } \\
\text { value }\end{array}$ & $\begin{array}{c}\text { Variance } \\
\text { (cum. var.) }\end{array}$ & $\begin{array}{c}\text { Cronbach's } \\
\alpha\end{array}$ \\
\hline \multirow{11}{*}{$\begin{array}{l}\text { Consumer's } \\
\text { needs for } \\
\text { uniqueness }\end{array}$} & \multirow{5}{*}{$\begin{array}{l}\text { Avoidance } \\
\text { of } \\
\text { similarity }\end{array}$} & $\begin{array}{l}\text { I do not use the products that I have } \\
\text { when it becomes popular among the } \\
\text { general public. }\end{array}$ & .792 & \multirow{5}{*}{2.944} & \multirow{5}{*}{$\begin{array}{c}13.725 \\
(33.390)\end{array}$} & \multirow{5}{*}{.759} \\
\hline & & $\begin{array}{l}\text { When my favorite product or brand gets } \\
\text { too popular, I lose interest in it. }\end{array}$ & .735 & & & \\
\hline & & $\begin{array}{l}\text { Whatever it is, the products and brands } \\
\text { that people are purchased regularly are } \\
\text { no longer worth for me. }\end{array}$ & .685 & & & \\
\hline & & $\begin{array}{l}\text { I disagree with what other people think } \\
\text { is the right thing to buy. }\end{array}$ & .635 & & & \\
\hline & & $\begin{array}{l}\text { I avoid products and brands that are } \\
\text { commonly used by ordinary people. }\end{array}$ & .613 & & & \\
\hline & \multirow{4}{*}{$\begin{array}{l}\text { Incompliant } \\
\text { choice }\end{array}$} & $\begin{array}{l}\text { I will continue to wear clothes the same } \\
\text { way, even if someone else says I am } \\
\text { wearing inappropriately for a social } \\
\text { situation. }\end{array}$ & .833 & \multirow{4}{*}{1.890} & \multirow{4}{*}{$\begin{array}{c}13.147 \\
(46.537)\end{array}$} & \multirow{4}{*}{.742} \\
\hline & & $\begin{array}{l}\text { I wear clothes what I want to wear } \\
\text { regardless of the situation or place. }\end{array}$ & .767 & & & \\
\hline & & $\begin{array}{l}\text { If I wear my clothes differently, I know } \\
\text { that others think strange, but I do not } \\
\text { care. }\end{array}$ & .658 & & & \\
\hline & & $\begin{array}{l}\text { I often dress freely, even if others are } \\
\text { offended. }\end{array}$ & .564 & & & \\
\hline & \multirow{2}{*}{$\begin{array}{l}\text { Unusual } \\
\text { choice }\end{array}$} & $\begin{array}{l}\text { I enjoy challenging the popular style } \\
\text { among people around me by purchasing } \\
\text { products that they will not accept. }\end{array}$ & .763 & \multirow{2}{*}{1.403} & \multirow{2}{*}{$\begin{array}{c}9.424 \\
(55.961)\end{array}$} & \multirow[t]{2}{*}{.628} \\
\hline & & $\begin{array}{l}\text { When I wear clothes, I often wear daring } \\
\text { dress that others would not accept. }\end{array}$ & .581 & & & \\
\hline
\end{tabular}

특성 욕구는 독창적 이미지 창출 욕구, 자유 표현 욕 구, 차별화 욕구, 유사성 회피 욕구, 비대중적 선택 욕 구 등으로 보다 세분화 되고 있다(Park \& Park, 2016; Yuan \& Kim, 2015)는 최근의 연구는 본 연구의 결과 를 뒷받침한다.

\section{2) Factor analysis and reliability verification of} fashion orientation

패션성향을 측정하는 문항은 모두 17 문항으로 요인 분석을 실시하여 요인 부하량이 낮은 4 문항을 제외한 13 문항을 최종 분석에 사용하였다. 요인추출방법은 주 성분분석을 행하였으며, Varimax 회전을 실시한 결과,
총 3 개의 요인이 도출되었고, 누적 설명력은 $60.135 \%$, 신뢰도 계수는 .701 .796으로 나타났다(Table 2).

요인 1 은 의복을 잘 입는 것은 중요하며, 개인의 삶에 영향을 미친다는 5 문항으로 구성되어 '의복 중 요' 요인으로 명명하였고, 요인 2는 패션을 선도하는 것에 관한 관심 및 자기 평가에 대한 4 문항으로 구성 되어 '패션 선도' 요인으로 명명하였다. 요인 3은 패 션 및 의복에 대한 관심을 표현하는 3 문항으로 구성 되어 '패션 관심' 요인으로 명명하였고, 반패션 태도 요인은 나타나지 않았다. 이는 본 연구의 응답자들이 패션 위크 기간에 패션쇼를 찾은 사람들로 한정되어 유행을 거부하거나, 유행에 대해 부정적인 문항은 신 
$<$ Table 2> Factor analysis and reliability verification of fashion orientation

\begin{tabular}{|c|c|c|c|c|c|c|}
\hline & Factors & Items & $\begin{array}{l}\text { Factor } \\
\text { loading }\end{array}$ & $\begin{array}{l}\text { Eigen- } \\
\text { value }\end{array}$ & $\begin{array}{c}\text { Variance } \\
\text { (cum. var.) }\end{array}$ & $\begin{array}{c}\text { Cronbach's } \\
\alpha\end{array}$ \\
\hline \multirow{13}{*}{$\begin{array}{l}\text { Fashion } \\
\text { orientation }\end{array}$} & \multirow{5}{*}{$\begin{array}{l}\text { Importance } \\
\text { of being } \\
\text { well-dressed }\end{array}$} & $\begin{array}{l}\text { What you think of yourself is reflected by } \\
\text { what you wear. }\end{array}$ & .848 & \multirow{5}{*}{5.113} & \multirow{5}{*}{23.693} & \multirow{5}{*}{.796} \\
\hline & & $\begin{array}{l}\text { If you want to keep ahead, you should dress } \\
\text { do so. }\end{array}$ & .748 & & & \\
\hline & & It is important to dress well. & .726 & & & \\
\hline & & Wearing good clothes is part of a good life. & .653 & & & \\
\hline & & $\begin{array}{l}\text { I buy at least one trendy fashion products } \\
\text { every season. }\end{array}$ & .544 & & & \\
\hline & \multirow{4}{*}{$\begin{array}{l}\text { Fashion } \\
\text { leadership }\end{array}$} & $\begin{array}{l}\text { I am confident in my ability to recognize } \\
\text { fashion trends. }\end{array}$ & .799 & \multirow{4}{*}{1.502} & \multirow{4}{*}{$\begin{array}{c}18.571 \\
(42.264)\end{array}$} & \multirow{4}{*}{.794} \\
\hline & & $\begin{array}{l}\text { I recognize fashion trends and want to be } \\
\text { one of the first to try them. }\end{array}$ & .778 & & & \\
\hline & & It is important for me to be a fashion leader. & .694 & & & \\
\hline & & $\begin{array}{l}\text { Since I am accepting new fashion trends for } \\
\text { the first time, many people think of me as a } \\
\text { fashion leader. }\end{array}$ & .687 & & & \\
\hline & \multirow{4}{*}{$\begin{array}{l}\text { Fashion } \\
\text { interest }\end{array}$} & $\begin{array}{l}\text { I never read fashion magazines or pay } \\
\text { attention to fashion trends. (-) }\end{array}$ & .770 & \multirow{4}{*}{1.202} & \multirow{4}{*}{$\begin{array}{c}17.872 \\
(60.135)\end{array}$} & \multirow{4}{*}{.701} \\
\hline & & $\begin{array}{l}\text { Because of my active life style, I need a } \\
\text { wide variety of clothes. }\end{array}$ & .732 & & & \\
\hline & & $\begin{array}{l}\text { Clothes are one of the most important ways } \\
\text { to express my personality. }\end{array}$ & .691 & & & \\
\hline & & $\begin{array}{l}\text { I spend a lot of time on fashion-related } \\
\text { activities. }\end{array}$ & .531 & & & \\
\hline
\end{tabular}

뢰도가 낮아 제거되었기 때문으로 보인다.

\section{3) Factor analysis and reliability verification of} consumption values

소비 가치는 27 문항을 중 요인 부하량이 낮은 2 문 항을 제외하고 25 문항을 최종 분석에 사용하였으며, 4가지 요인이 도출되었다. 총 설명력은 $54.476 \%$, 신 뢰도는 .729 .897로 나타났으며, 결과는 〈Table 3〉과 같다.

요인 1 은 상품을 통해 얻는 스스로의 만족감과 개성 표현을 중시한다는 내용이 포함되어 ‘주관적 가치'로 명 명하였으며, 11 문항으로 구성되었다. 요인 2는 다른 사 람들이 자신에 대해 어떻게 생각할지에 더 많은 주의
를 기울이며 다른 사람에게 호감을 줄 수 있는 제품을 선호한다는 문항을 포함하여 6문항으로 구성되어 '동 조적 가치'로 명명하였다. 요인 3은 연령과 신분, 지위 에 맞는 옷차림을 한다는 내용으로 3 문항으로 구성되 어 '사회적 가치'라고 명명하였으며, 요인 4는 제품의 소재와 관리의 용의성을 중요하게 생각한다는 5 문항으 로 구성되어 '기능적 가치’로 명명하였다.

\section{Effects of consumer's need for uniqueness on} fashion orientation

소비자의 독특성 욕구가 소비자의 패션성향에 미 치는 영향을 알아보기 위해 소비자 독특성 욕구의 네 요인을 독립변수로, 패션 성향의 세 요인을 종속변수 
$<$ Table 3> Factor analysis and reliability verification of consumption values

\begin{tabular}{|c|c|c|c|c|c|c|}
\hline & Factors & Items & $\begin{array}{l}\text { Factor } \\
\text { loading }\end{array}$ & $\begin{array}{c}\text { Eigen- } \\
\text { value }\end{array}$ & $\begin{array}{c}\text { Variance } \\
\text { (cum. var.) }\end{array}$ & $\begin{array}{c}\text { Cronbach's } \\
\alpha\end{array}$ \\
\hline \multirow{25}{*}{$\begin{array}{l}\text { Consumption } \\
\text { values }\end{array}$} & \multirow{11}{*}{$\begin{array}{l}\text { Individuality } \\
\text { value }\end{array}$} & $\begin{array}{l}\text { I set great store by my own satisfaction with } \\
\text { the products. }\end{array}$ & .708 & \multirow{11}{*}{4.806} & \multirow{11}{*}{19.223} & \multirow{11}{*}{.862} \\
\hline & & I like products that express my personality well. & .695 & & & \\
\hline & & $\begin{array}{l}\text { I think it is important whether the product } \\
\text { represents my image. }\end{array}$ & .689 & & & \\
\hline & & $\begin{array}{l}\text { I want to get attention from others by clothes } \\
\text { or accessories. }\end{array}$ & .685 & & & \\
\hline & & $\begin{array}{l}\text { I think it is important whether the product } \\
\text { arouse my curiosity. }\end{array}$ & .674 & & & \\
\hline & & I like products that are different from others. & .660 & & & \\
\hline & & I prefer a unique style that amazes people. & .657 & & & \\
\hline & & I like products that are unique in design or color. & .631 & & & \\
\hline & & $\begin{array}{l}\text { I emphasize whether the product is a new style } \\
\text { rather than a monolithic design that is currently } \\
\text { popular. }\end{array}$ & .587 & & & \\
\hline & & I emphasize whether I feel happy with the product. & .571 & & & \\
\hline & & I am happy to talk about the products I bought. & .564 & & & \\
\hline & \multirow{6}{*}{$\begin{array}{l}\text { Conformity } \\
\text { value }\end{array}$} & $\begin{array}{l}\text { I like products that can get good ratings } \\
\text { (feeling, approval) from others. }\end{array}$ & .864 & \multirow{6}{*}{3.235} & \multirow{6}{*}{$\begin{array}{c}12.939 \\
(32.163)\end{array}$} & \multirow{6}{*}{.803} \\
\hline & & I like products that can appeal to the opposite sex. & .756 & & & \\
\hline & & I care much about what people think of me. & .734 & & & \\
\hline & & $\begin{array}{l}\text { I think it is important to having confidence by } \\
\text { owning a particular brand. }\end{array}$ & .636 & & & \\
\hline & & $\begin{array}{l}\text { It is important to me the response of friends } \\
\text { and people to products or brands I bought. }\end{array}$ & .620 & & & \\
\hline & & $\begin{array}{l}\text { I want to belong to a group of people who buy } \\
\text { certain products. }\end{array}$ & .532 & & & \\
\hline & \multirow{3}{*}{$\begin{array}{l}\text { Social } \\
\text { value }\end{array}$} & $\begin{array}{l}\text { I consider whether the product meets my age, } \\
\text { job, and gender. }\end{array}$ & .896 & \multirow{3}{*}{2.899} & \multirow{3}{*}{$\begin{array}{c}11.595 \\
(43.758)\end{array}$} & \multirow{3}{*}{.897} \\
\hline & & $\begin{array}{l}\text { I consider whether the product fits well with } \\
\text { my group (friends, school, work place). }\end{array}$ & .819 & & & \\
\hline & & $\begin{array}{l}\text { I consider whether a product can represent well } \\
\text { my social status. }\end{array}$ & .761 & & & \\
\hline & \multirow{5}{*}{$\begin{array}{l}\text { Functional } \\
\text { value }\end{array}$} & $\begin{array}{l}\text { When I choosing a product, I consider whether } \\
\text { the product is well stitched }\end{array}$ & .760 & \multirow{5}{*}{2.680} & \multirow{5}{*}{$\begin{array}{c}10.719 \\
(54.476)\end{array}$} & \multirow{5}{*}{.729} \\
\hline & & $\begin{array}{l}\text { When I choosing a product, I consider whether } \\
\text { the fabric is good or not. }\end{array}$ & .717 & & & \\
\hline & & $\begin{array}{l}\text { I think the ease of care and maintenance of } \\
\text { products is important. }\end{array}$ & .670 & & & \\
\hline & & $\begin{array}{l}\text { When I choosing a product, I consider whether } \\
\text { the product can be used frequently. }\end{array}$ & .604 & & & \\
\hline & & $\begin{array}{l}\text { I like products that have better performance } \\
\text { (thermal, breathability) than designs and colors. }\end{array}$ & .531 & & & \\
\hline
\end{tabular}


로 하여 회귀분석을 실시한 결과, 회귀 분석 모델은 통 계적으로 유의한 예측력을 가지는 것으로 나타났다. 결 과를 살펴보면, 소비자 독특성 욕구 중에서 독창적 선택 요인은 패션성향의 세 요인 모두에서 가장 중요 한 설명력을 보였다(Table 4). 즉, 패션성향은 사회 집 단의 규범을 깨지 않는 범위 내에서 자신을 독립적으 로 표현하고자 하는 독특성의 차원으로 설명할 수 있 음을 보여주며, 이는 패션성향과 소비자 독특성 욕구
의 관계를 설명한 Jeon and Park(2005)의 연구와 일치 하는 결과이다. 또한 소비자의 독특성 욕구 중 비대 중적 선택 욕구는 패션 성향 중 패션 선도 성향에 유 의한 예측력을 가지는 것으로 나타났다. 즉, 패션 선 도 성향은 현재의 유행에 도전하거나, 대담한 옷차림 을 하는 비대중적 선택 욕구로 설명할 수 있다. 한편, 유사성 회피 욕구와 비순응적 선택 욕구는 패션성향 에 영향을 미치지 못하는 것으로 나타났다.

$<$ Table 4> Effects of consumer's need for uniqueness on fashion orientation

\begin{tabular}{|c|c|c|c|c|c|c|c|c|}
\hline \multirow{2}{*}{\multicolumn{2}{|c|}{ Dependent variable }} & \multicolumn{7}{|c|}{ Independent variable (Importance of being well-dressed) } \\
\hline & & $\mathrm{B}$ & SE & $\beta$ & $t$ & $p$ & $F$ & $R^{2}$ \\
\hline \multicolumn{2}{|c|}{ Constant } & 1.628 & .573 & & $2.839^{* *}$ & .006 & \multirow{5}{*}{$8.486^{* * *}$} & \multirow{5}{*}{.327} \\
\hline \multirow{4}{*}{$\begin{array}{l}\text { Consumer's } \\
\text { need for } \\
\text { uniqueness }\end{array}$} & $\begin{array}{l}\text { Creative } \\
\text { choice }\end{array}$ & .562 & .140 & .496 & $4.016^{* * *}$ & .000 & & \\
\hline & $\begin{array}{c}\text { Avoidance } \\
\text { of similarity }\end{array}$ & -.164 & .103 & .055 & -1.588 & .117 & & \\
\hline & $\begin{array}{c}\text { Incompliant } \\
\text { choice }\end{array}$ & .084 & .089 & .266 & .949 & .346 & & \\
\hline & $\begin{array}{l}\text { Unusual } \\
\text { choice }\end{array}$ & .156 & .094 & .085 & 1.663 & .101 & & \\
\hline \multirow{2}{*}{\multicolumn{2}{|c|}{ Dependent variable }} & \multicolumn{7}{|c|}{ Independent variable (Fashion leadership) } \\
\hline & & $\mathrm{B}$ & SE & $\beta$ & $t$ & $p$ & $F$ & $R^{2}$ \\
\hline \multicolumn{2}{|c|}{ Constant } & .213 & .546 & & .389 & .698 & \multirow{5}{*}{$14.4501^{* * *}$} & \multirow{5}{*}{.453} \\
\hline \multirow{4}{*}{$\begin{array}{l}\text { Consumer's } \\
\text { need for } \\
\text { uniqueness }\end{array}$} & $\begin{array}{l}\text { Creative } \\
\text { choice }\end{array}$ & .527 & .133 & .385 & $3.957^{* * *}$ & .000 & & \\
\hline & $\begin{array}{l}\text { Avoidance } \\
\text { of similarity }\end{array}$ & -.034 & .098 & -.032 & -.344 & .732 & & \\
\hline & $\begin{array}{c}\text { Incompliant } \\
\text { choice }\end{array}$ & .150 & .084 & .178 & 1.779 & .080 & & \\
\hline & $\begin{array}{c}\text { Unusual } \\
\text { choice }\end{array}$ & .277 & .089 & .324 & $3.099^{* *}$ & .003 & & \\
\hline \multirow{2}{*}{\multicolumn{2}{|c|}{ Dependent variable }} & \multicolumn{7}{|c|}{ Independent variable (Fashion interest) } \\
\hline & & $\mathrm{B}$ & SE & $\beta$ & $t$ & $p$ & $F$ & $R^{2}$ \\
\hline \multicolumn{2}{|c|}{ Constant } & 2.317 & .548 & & $4.228^{* * *}$ & .000 & \multirow{5}{*}{$6.603^{* * *}$} & \multirow{5}{*}{.274} \\
\hline \multirow{4}{*}{$\begin{array}{l}\text { Consumer's } \\
\text { need for } \\
\text { uniqueness }\end{array}$} & $\begin{array}{c}\text { Creative } \\
\text { choice }\end{array}$ & .547 & .134 & .459 & $4.096^{* * *}$ & .000 & & \\
\hline & $\begin{array}{l}\text { Avoidance } \\
\text { of similarity }\end{array}$ & -.093 & .099 & -.102 & -.941 & .350 & & \\
\hline & $\begin{array}{c}\text { Incompliant } \\
\text { choice }\end{array}$ & -.119 & .085 & -.162 & -1.408 & .163 & & \\
\hline & $\begin{array}{l}\text { Unusual } \\
\text { choice }\end{array}$ & .120 & .090 & .162 & 1.343 & .184 & & \\
\hline
\end{tabular}

${ }^{*} p<.05,{ }^{* *} p<.01,{ }^{* * *} p<.001$ 


\section{Effects of consumer's need for uniqueness on} consumption value

소비자의 독특성 욕구가 소비자의 소비가치에 미 치는 영향을 알아보기 위해 소비자 독특성 욕구의 네 요인을 독립변수로, 소비가치의 네 요인을 종속변수로 하여 회귀분석을 실시하였다. 그 결과, 소비가치 중 주 관적 가치와 사회적 가치의 회귀 분석 모델은 통계적 으로 유의한 예측력을 가지는 것으로 나타났으나, 동 조적 가치와 기능적 가치의 회귀 분석 모델은 통계적 으로 유의하지 않은 것으로 나타났다(Table 5). 결과 에 따르면 자신의 독특한 스타일을 나타내기를 원하 는 독창적 선택욕구와 비순응적 선택 욕구는 의류제 품 소비 시 자신의 이미지를 나타내기 위해 사람들을 놀라게 하는 독특한 제품을 선호하며, 무엇보다 제품 을 통해 느끼는 스스로의 만족감과 행복감을 중요하 게 생각하는 주관적 가치에 영향을 끼쳤다.

한편, 소비자의 소비가치 중 사회적 가치에는 독특 성 욕구 중에서 비순응적 선택 욕구만이 유의한 영향
을 미치는 것으로 나타났다. 즉, 다른 사람들의 평가 나 사회적 규범에 상관 없이 자신의 스타일을 고집하 는 비순응적 선택 욕구가 높을수록 의복 소비 시 자 신의 사회적 지위와 자신이 속한 집단, 사회의 규범 을 고려하는 사회적 가치를 적게 지각하였다. 한편, 유 사성 회피 욕구와 비대중적 선택 욕구는 소비가치에 영향을 미치지 못하는 것으로 나타났다.

\section{Conclusion}

본 연구는 소비자의 독특성 욕구가 패션성향과 소 비가치에 미치는 영향을 알아보기 위해 독특성 욕구 가 높은 소비자들만을 대상으로 연구를 진행하였으며, 연구 결과, 소비자 독특성 욕구는 ‘독창적 선택', ‘유 사성 회피’, ‘비순응적 선택', ‘비대중적 선택'의 4가지 요인이 도출되었다. 소비자의 독특성 욕구와 패션성 향과의 관계를 알아보기 위해, 패션성향의 세 요인(의 복중요, 패션선도, 패션관심)을 종속변수로, 소비자 독

$<$ Table 5> Effects of consumer's need for uniqueness on consumption values

\begin{tabular}{|c|c|c|c|c|c|c|c|c|}
\hline \multirow{2}{*}{\multicolumn{2}{|c|}{ Dependent variable }} & \multicolumn{7}{|c|}{ Independent variable (Individuality value) } \\
\hline & & $\mathrm{B}$ & SE & $\beta$ & $t$ & $p$ & $F$ & $R^{2}$ \\
\hline \multicolumn{2}{|c|}{ Constant } & 1.072 & .418 & & $2.562^{*}$ & .013 & \multirow{5}{*}{$14.550^{* * *}$} & \multirow{5}{*}{.454} \\
\hline \multirow{4}{*}{$\begin{array}{l}\text { Consumer's } \\
\text { need for } \\
\text { uniqueness }\end{array}$} & $\begin{array}{l}\text { Creative } \\
\text { choice }\end{array}$ & .521 & .102 & .496 & $5.107^{* * *}$ & .000 & & \\
\hline & $\begin{array}{l}\text { Avoidance } \\
\text { of similarity }\end{array}$ & .044 & .075 & .055 & .588 & .559 & & \\
\hline & $\begin{array}{c}\text { Incompliant } \\
\text { choice }\end{array}$ & .172 & .065 & .266 & $2.664^{*}$ & .010 & & \\
\hline & $\begin{array}{l}\text { Unusual } \\
\text { choice }\end{array}$ & .055 & .068 & .085 & .809 & .421 & & \\
\hline \multirow{2}{*}{\multicolumn{2}{|c|}{ Dependent variable }} & \multicolumn{7}{|c|}{ Independent variable (Social value) } \\
\hline & & $\mathrm{B}$ & SE & $\beta$ & $t$ & $p$ & $F$ & $R^{2}$ \\
\hline \multicolumn{2}{|c|}{ Constant } & 3.337 & 1.077 & & $3.097^{* *}$ & .003 & \multirow{5}{*}{$3.014^{*}$} & \multirow{5}{*}{.147} \\
\hline \multirow{4}{*}{$\begin{array}{l}\text { Consumer's } \\
\text { need for } \\
\text { uniqueness }\end{array}$} & $\begin{array}{l}\text { Creative } \\
\text { choice }\end{array}$ & .506 & .263 & .234 & 1.926 & .058 & & \\
\hline & $\begin{array}{l}\text { Avoidance } \\
\text { of similarity }\end{array}$ & -.248 & .194 & -.150 & -1.279 & .205 & & \\
\hline & $\begin{array}{l}\text { Incompliant } \\
\text { choice }\end{array}$ & -.337 & .167 & -.253 & $-2.026^{*}$ & .047 & & \\
\hline & $\begin{array}{l}\text { Unusual } \\
\text { choice }\end{array}$ & -.118 & .176 & -.087 & -.669 & .506 & & \\
\hline
\end{tabular}

${ }^{* * *} p<.001,{ }^{* *} p<.01,{ }^{*} p<.05$ 
특성 욕구의 네 요인(독창적 선택, 유사성 회피, 비순 응적 선택, 비대중적 선택)을 독립변수로 각각 회귀분 석을 실시한 결과, 소비자의 독특성 욕구 중에서 독창 적 선택욕구는 패션성향의 모든 요인에서 가장 중요 한 설명력을 보이고 있는 것으로 나타났으며, 비대중 적 선택 욕구는 패션 성향 중 패션 선도 성향에 유의 한 예측력을 가지는 것으로 나타났다. 반면, 유사성 회 피 욕구와 비순응적 선택 욕구는 패션성향에 아무런 영향을 미치지 못하는 것으로 나타났다.

또한 소비자의 독특성 욕구와 소비가치와의 관계를 알아보기 위해, 소비가치의 네 요인(주관적 가치, 동 조적 가치, 사회적 가치, 기능적 가치)을 종속변수로, 소비자 독특성 욕구의 네 요인(독창적 선택, 유사성 회피, 비순응적 선택, 비대중적 선택)을 독립변수로 각 각 회귀분석을 실시한 결과, 소비자의 독특성 욕구 중 에서 독창적 선택욕구와 비순응적 선택 욕구는 소비 가치 중 주관적 가치에 영향을 미치는 것으로 나타났 다. 즉, 자신만의 스타일을 창조하여 남과 차별화 되 고자 하는 소비자들과 스스로가, 그리고 주변에서 패 션리더로 생각하는 소비자들은 의복 소비 시 주관적인 가치를 중요하게 생각하고, 스스로에게 만족감이나 행복감을 주는 제품을 선호한다. 또한 사회적 불승인, 주위의 비난을 감수하면서도 원하는 옷을 입으려고 하는 사람들은 의복 소비 시 자신의 사회적 지위와 소 속 집단의 규범을 고려하기 보다는 자신의 스타일을 고집하는 것을 알 수 있었다.

본 연구의 결과를 바탕으로 앞으로 패션 회사들은 독특성 욕구가 높은 소비자들에게 지속적으로 다양 한 스타일을 제공할 수 있도록 제품과 컨텐츠 개발에 노력을 기울여야 하며, 그들 스스로의 만족감을 고취 시킬 수 있는 마케팅을 전개해 나가야 할 것이다. 특 히 독자적 선택욕구와 비대중적 선택 욕구가 높은 소 비자들은 유행에 대해 부정적이고, 사회적으로 좋은 평가를 받는 스타일이나 제품을 기피하는 경향이 있 으므로, 이러한 소비자들을 대상으로 사업을 전개할 때는 제품이나 브랜드의 아이덴티를 강조하거나, 희 소성, 다른 제품과의 차별점을 강조하는 것이 필요하 다. 또한 사회적 규범과 주위의 평판에 관계없이 스 스로가 원하는 옷을 고집하는 비순응적 선택 욕구가 높은 소비자들을 위해 착용자 스스로가 독창적인 방
법으로 제품을 변화시킬 수 있는 기능과 디자인을 갖 춘 제품, 혹은 다양한 크기와 디자인의 액세서리를 이용해 세상에 하나밖에 없는 나만의 제품을 만들 수 있는 커스터 마이즈된 제품을 개발한다면 이들 소비 자들을 만족시킬 수 있을 것으로 보인다.

본 연구는 독특성 욕구를 가진 소비자의 차원을 밝 히고, 이들의 패션성향과 소비가치에 대해 밝히고자 하였으며, 실제 독특성 욕구가 높은 소비자들을 대상 으로 연구를 진행했다는 데, 그 의의가 있다고 할 수 있다. 그러나 설문 대상을 찾는 과정에서 독특성 욕 구가 높은 소비자들이 많이 찾을 것으로 예상되는 이 벤트를 서울 패션 위크로 한정하여 응답자의 대부분 이 패션 관련 산업 종사자 및 전공자이며, 10 대와 20 대가 대부분이었다. 본 연구의 결과를 전체 소비자로 확대 해석하기에는 다소 무리가 있을 수 있으므로 후 속 연구에서는 보다 다양한 소비자들을 대상으로 연 구가 진행되어야 할 것이며, 향후 소비자 독특성 욕 구의 형성에 영향을 미치는 다양한 요인들을 밝히는 연구도 진행되어야 할 것이다.

\section{References}

Belk, R. W. (1988). Possessions and the extended self. Journal of Consumer Research, 15(2), 139-168. doi:10.1086/209154

Bertrandias, L., \& Goldsmith, R. E. (2006). Some psychological motivations for fashion opinion leadership and fashion opinion seeking. Journal of Fashion Marketing and Management: An International Journal, 10(1), 25-40. doi:10.1108/13612 020610651105

Gim, W.-S., \& Ryu, Y. J. (2003). Korean version of consumer's need for uniqueness scale(K-CNFU): Development and validation. The Korean Journal of Consumer and Advertising Psychology, 4(1), 79-101.

Gross, H. E. (1977). Micro and macro level implications for a sociology of virtue: The case of draft protesters to the Vietnam War. The Sociological Quarterly, 18(3), 319-339. doi:10.1111/j.1533-8525. 
1977.tb01418.x

Gutman, J., \& Mills, M. K. (1982). Fashion life style, self-concept, shopping orientation, and store patronage: An integrative analysis. Journal of Retailing, 58(2), 64-86.

Heckert, D. M. (1989). The relativity of positive deviance: The case of the French impressionists. Deviant Behavior, 10(2), 131-144. doi:10.1080/01639625. 1989.9967806

Holt, D. B. (1995). How consumers consume: A typology of consumption practices. Journal of Consumer Research, 22(1), 1-16. doi:10.1086/209431

Jeon, K. S., \& Park, H. J. (2005). The effect of fashion orientation and consumer needs for uniqueness on buying intentions for luxury brands. Journal of the Korean Society of Clothing and Textiles, 29(2), 231-241.

Kim, I. (2010). The influence of the consumers value and experience quality on the effects of scarcity message types. Unpublished master's thesis, Duksung Women's University, Seoul, Korea.

Kim, K. H., \& Chung, S. J. (2000). A study on relationships between clothing conformity and clothing attitudes of middle and high school students: Focused on Seoul residents. Journal of the Korean Society of Clothing and Textiles, 24(3), 401-411.

Kim, S. H. (1999). A study on the structure of clothing consumption values and the relation between clothing consumption values and, clothing involvement and fashion leadership. Unpublished doctoral dissertation, Ewha Woman's University, Seoul, Korea.

Kim, Y.-H. (2008). An empirical examination of consumers' innovation adoption: The role of innovativeness, fashion orientation, and utilitarian and hedonic consumers' attitudes. Unpublished master's thesis. The University of North Carolina at Greensboro, NC, USA.

Knight, D. K., \& Kim, E. Y. (2007). Japanese consumers' need for uniqueness: Effects on brand perceptions and purchase intention. Journal of Fashion Marketing and Management: An International Journal, 11(2), 270-280. doi:10.1108/ 13612020710751428

Kron, J. (1983). Home-psych: The social psychology of home and decoration. New York: Potter.

Lee, K.-H., \& Choi, J.-Y. (2011). Fashion orientation, goal-directed or experiential motivations, shopping flow experience and purchasing behavior of fashion products. Journal of the Korean Fashion \& Costume Design Association, 13(2), 185-193.

Lumpkin, J. R. (1985). Shopping orientation segmentation of the elderly consumer. Journal of the Academy of Marketing Science, 13(1), 271-289. doi:10.1007/ BF02729720

Lynn, M., \& Harris, J. (1997). The desire for unique consumer products: A new individual differences scale. Psychology \& Marketing, 14(6), 601-616. doi:10.1002/(SICI)1520-6793(199709)14:6<601:: AID-MAR5>3.0.CO;2-B

Park, S.-J., \& Park, S.-K. (2016). The effect of consumer's need for uniqueness on brand, store and price switching intention. The Journal of the Korean Society of Knit Design, 14(3), 1-9.

Sheth, J. N., Newman, B. I., \& Gross, B. L. (1991). Why we buy what we buy: A theory of consumption values. Journal of Business Research, 22(2), 159170. doi:10.1016/0148-2963(91)90050-8

Simonson, I., \& Nowlis, S. M. (2000). The role of explanations and need for uniqueness in consumer decision making: Unconventional choices based on reasons. Journal of Consumer Research, 27(1), 4968. doi: $10.1086 / 314308$

Snyder, C. R., \& Fromkin, H. L. (1977). Abnormality as a positive characteristic: The development and validation of a scale measuring need for uniqueness. Journal of Abnormal Psychology, 86(5), 518-527. doi:10.1037/0021-843X.86.5.518

Solomon, M. R., \& Rabolt, N. J. (2004). Consumer behavior: In fashion. Upper Saddle River, NJ: 
Prentice-Hall.

Tepper, K., \& Hoyle, R. H. (1996). Latent variable models of need for uniqueness. Multivariate Behavioral Research, 31(4), 467-494. doi:10.1207/s15 327906mbr3104_4

Tian, K. T., \& McKenzie, K. (2001). The long-term predictive validity of the consumers' need for uniqueness scale. Journal of Consumer Psychology, 10(3), 171-193. doi:10.1207/s15327663jcp1003_5

Tian, K. T., Bearden, W. O., \& Hunter, G. L. (2001). Consumers' need for uniqueness: Scale development and validation. Journal of Consumer Research, 28(1), 50-66. doi:10.1086/321947

Vinson, D. E., Scott, J. E., \& Lamont, L. M. (1977).
The role of personal values in marketing and consumer behavior. Journal of Marketing, 41(2), 44-50. doi: $10.2307 / 1250633$

Workman, J. E., \& Kidd, L. K. (2000). Use of the need for uniqueness scale to characterize fashion consumer groups. Clothing and Textiles Research Journal, 18(4), 227-236. doi:10.1177/0887302X0 001800402

Yuan, L., \& Kim, J. H. (2015). The influence of the uniqueness for need on impulsive purchase, regrets and satisfaction: Focusing on the Chinese fashion product consumers. Journal of Product Research, 33(2), 105-116. 